
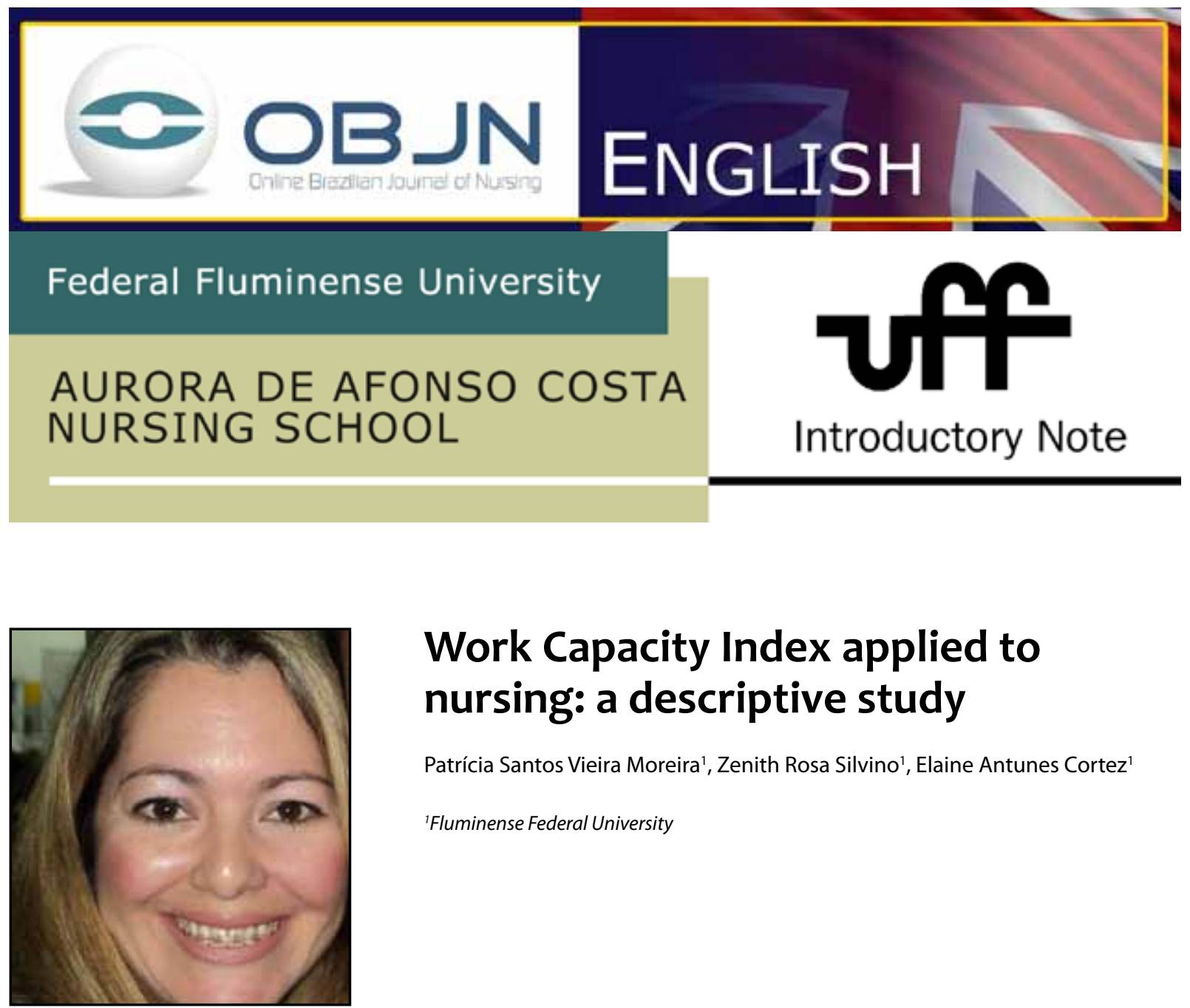

\title{
Work Capacity Index applied to nursing: a descriptive study
}

Patrícia Santos Vieira Moreira' ${ }^{1}$ Zenith Rosa Silvino', Elaine Antunes Cortez

${ }^{1}$ Fluminense Federal University

\begin{abstract}
Aims: to assess the Work Capacity among newly recruited nurses, professionals who have worked as nurses for 15 years, and those at the final years of their career at the Antonio Pedro University Hospital (HUAP); to correlate the Work Capacity Index (WCI) of each group; to implement a Work Capacity methodology in order to observe the state of health of the nursing staff working at the HUAP.

Method: This is an observational descriptive study using a quantitative correlational approach. It has been carried out through a WCI questionnaire that is proposed by the Finnish Occupational Health Institute. The research participants include nursing assistants, technical nurses and graduated nurses working at the HUAP. The ethical aspects have been respected, complying with the law resolution 196/96. This project is under development and aims to analyze and verify the relationship between career length, the workers' state of health and their work capacity.
\end{abstract}

Descriptors: Occupational Health; Nursing, Team; Work Capacity Evaluation. 


\section{SITUATION PROBLEM AND ITS SIGNIFICANCE}

The health deterioration among nursing professionals is closely related to the work conditions, for instance: intense and long working hours; staff turnovers; and frequent reassignments. Since the healthcare practice deals with illness, pain and death, it is likely to cause physical and mental distress to the professionals. In this context, it is crucial the development of tools to promote self-care and keep the work capacity level among these professionals. The Work Capacity Index (WCI) is a protocol used to assess health work capacity; thus, it can help workers and managers to implement occupational health programs.

The work capacity is essential for human wellbeing and it might not remain satisfactory throughout time, unless some self-care attitudes are taken. Although it is affected by several factors, the workers can have influence upon them through their own actions ${ }^{(1)}$.

The work capacity concept is used to define "how well is or will be the professional at present or in the near future. Also, it assesses the worker capacity of carrying out their tasks in the face of work demands, their state of health and physical and mental capacity."(1:2)

Nursing professionals show few signs of self-care and are reckless in regard to accidents. They expose themselves not only to biological risks, but also to psycho-social and ergonomic ones. Nevertheless, few preventive and health promoting actions have been addressed to them. An accident can cause many psycho-social consequences to the worker's life, including changes in the professional, social and family relationships. Such consequences include the psycho-social reactions to post-exposure prophylaxis, which are quite common among healthcare profes- sionals due to occupational exposure and emotional impact ${ }^{(2)}$.

Work balance and fatigue might or might not cause a psychic load, depending on the level of work demand ${ }^{(3)}$. Workers have many ways of letting off steam such as psychomotor loads or somatization process ${ }^{(3)}$, which might affect their work capacity ${ }^{(3)}$.

After implementing the $\mathrm{WCI}$ methodology at the aforementioned hospital, we intended to observe the workers' state of health, to instruct and to refer them according to the $\mathrm{WCI}$ results.

\section{AIMS}

To assess the Work capacity among newly recruited nurses, professionals who have worked as nurses for 15 years, and those at the final years of their career at the Antonio Pedro University Hospital (HUAP); to correlate the Work Capacity Index (WCI) of each group; to implement a Work Capacity methodology in order to observe the state of health of the nursing staff working at the HUAP.

\section{ASSUMPTION}

It is anticipated that the work capacity is closely related to career length and also that it is more likely to happen even earlier among nursing professionals.

\section{METHOD}

This is an observational descriptive study using a quantitative correlational approach. The research setting is the HUAP, a university hospital that provides tertiary and quaternary levels of care in the metropolitan area of Rio de 
Janeiro. The research participants are nursing professionals. The sample size calculation, with a level of significance of 0,05 and margin of error of 0,07 , has determined the following research sample: 79 graduated nurses, 96 technical nurses and 80 nursing assistants. The inclusion criteria are: among the newly recruited group, we have considered those nurses who have worked up to 5 years at the HUAP; for group 2, the participants must have worked as nurses for 15 to 25 years; for group 3, the participants must have worked as nurses for over 25 years. The exclusion criteria is: to be away from work during the data collection period.

For data collection, a WCl questionnaire was used. It is a self-applied tool, composed of 7 items and each item is worth a pre-determined score. Data collection has been undertaken between February and April, 2013.

For data analysis, this study has used $\mathrm{SAS}^{\circ}$ 9.1(9.01.01M3P020206) software, licensed by Dankook University, site 0038249001 . The relationship between career length and WCI was verified through Spearman's correlation coefficient, since the variables were not linear.

This research is still under discussion and development.

\section{REFERENCES}

1. Martinez MC, Latorre MRDO, Fischer FM. Capacidade para o Trabalho: Revisão de Literatura. Ciênc saúde coletiva. 2010. 15 Suppl 1: 1553-61.

2. Simão SAF, Silvino ZR. Profile of accidents with biological material occurred between health professionals in hospitals in Niterói - RJ - Brazil. Online braz j nurs [Internet]. 2010 [cited 2013 Sept 9]; 9 (1): [about 3 p.]. Available from: http:// www.objnursing.uff.br/index.php/nursing/article/view/j.1676-4285.2010.2688/593

3. Dejours C, Abdoucheli E, Jayet C. Psicodinâmica do trabalho, contribuições da escola Dejouriana à análise da relação prazer, sofrimento e trabalho. São Paulo: Atlas; 2012.

Project details: This is a Dissertation Research Project from the Social Care Master's Program- MPEA/UFF.

This research has been approved by the IRB of UFF, under protocol no. CAAE: 11069612.1.0000.5243

Researcher's Mentor: Zenith Rosa Silvino

Co-mentor: Elaine Antunes Cortez

Financial support: PROPPI/UFF

Received: $11 / 03 / 2013$

Revised: 08/08/2013

Approved: 10/08/2013 